\title{
EXPERIMENTING WITH DIGITAL TELEVISION LEARNING ENVIRONMENTS
}

\author{
Päivi Aarreniemi-Jokipelto ${ }^{1}$, Juha Tuominen ${ }^{1}$, Seppo Kalli ${ }^{2}$ and Tommi \\ Riikonen ${ }^{3}$ \\ ${ }^{1}$ Industrial IT Laboratory, Helsinki University of Technology, ${ }^{2}$ Digital Media Institute, \\ Tampere University of Technology, ${ }^{3}$ Ortikon Interactive Ltd.
}

\begin{abstract}
Digital media environment has been changed significantly during the last few years. The huge progress in communication technology and the launch of digital television have open up new opportunities for distance learning. Interactive digital television is providing a new and flexible learning environment. The Industrial IT Laboratory of Helsinki University of Technology has made research in utilising digital TV as a learning environment for University courses and the students have had a chance to study using digital TV since September 2002.
\end{abstract}

Key words: Interactive, digital television, learning models, Higher Education,

\section{INTRODUCTION}

The Industrial IT Laboratory in Helsinki University of Technology is responsible for the Motive- Modern Data Networks in Education -project. Motive is a content-production development project financed by the European Social Fund. The objective is to use Internet and digital TV to create interactive and flexible courses. The overall project emphasizes several research interests within the learning service deployment chain, from service editing and broadcasting finally to utilization at the student side together with involvement of different feedback mechanisms.

According to Garito (2001) digital TV can give concrete answers to lifelong educational needs and it can be a useful tool for the creation of new knowledge and new skills. 
The use of digital TV as a learning environment does not mean that the learner is seen in a passive role, just watching the television. In our case, the learner has a very active role in the learning process. She has a total control of the material and can pick the parts best suitable for her purposes. This type of study is very flexible for the student as she can utilise hyperlinks in order to move from one place to another in the study material, in the same way as on the Internet. Also, the exercises included in each section of study can be done by pressing buttons on the remote control.

Ortikon Interactive Ltd., which specialises in digital television technology and services, is responsible for supplying the technology that is required for the studying environment. The technology platform and the necessary products were already in existence. What is novel is their application to the field of electronic learning. The Motive -project combines Ortikon Interactive's technical expertise and the Industrial IT Laboratory's expertise in online pedagogy and content production.

In this paper, we report the first experiences both from student and content producer's point of view. The first course where digital TV was used was Local Demands for Global Enterprising. The feedback from the students was very positive and encouraging. They felt that digital television is very suitable for educational purposes and that they would like to study more utilising digital TV.

\section{TECHNOLOGY}

The core of the learning environment is the ORTIKON ACE ${ }^{\circledR}$ Learning Suite, developed specially for the management of interactive digital TV services for learning purposes. It makes adding, maintaining and finally distributing of learning services simple without need for special IT skills. It is "the heart" of the system, which connects all the needed sub-systems (content databases, control computer, return channel, broadcast channel, etc.) to each other and handles the feeding of the content and applications to the broadcasting channel via object carousel servers. The system also receives the requests coming from the digital television receiver via return channel.

It is by means of the Learning Suite that the content producer creates and maintains its services and transmits them to the recipient. Also, two interactive digital TV applications are utilised: digital television portal displays the learning content on the TV screen where it can be browsed using a remote control, while digital TV real-time discussion forum is used for organising any discussions that may be necessary between tutor and students. 
Remote control operated virtual keyboard on TV screen can be used for entering text. It is also possible to utilise other types of devices such as GSM phone's SMS or MMS messages for providing the content to the learning system.

There is a way to control the access to the digital television services. Students will use both a username and a password to enter and study in the course. Also the legal aspect is considered; all students participating this type of course have to sign a form in advance, stating that they allow their names to be seen in the conversations in digital TV.

\section{PEDAGOGY}

It is not enough to have only learning material in digital form. The whole learning process, including conversations and assignments, should be in digital environment as depicted in Figure 1.

\begin{tabular}{|l|ll|}
\hline \multicolumn{2}{|c|}{ Learning material } & \multicolumn{1}{c|}{ Learning process } \\
$\bullet \quad$ lecture material & $\bullet$ & conversations \\
& $\bullet$ & assignments \\
& $\bullet$ & guiding and tutoring \\
& $\bullet$ & groupwork \\
& $\bullet$ & creating and sharing new \\
& & information \\
\hline
\end{tabular}

Table1. Learning in Digital television.

Hiltz (1998) says that the premise from which all online teaching should begin is that the goal is to build a learning community for exchanging of ideas, information and a feeling of community. Using a return channel in digital TV makes that possible. Students would have a chance to discuss with other students, experts and tutors. They would be able to share knowledge and their competence with each other. In the interaction with each other, students would actually be able to create new knowledge. That is very important, especially in the areas where information is getting obsolete very fast. With the help of the tutor the learning process is always guided to the right direction. Also co-operation with other students, experts and tutor is playing an important role.

We are using problem-based learning (Hakkarainen et al., 2001) as a background theory in our courses during the coming autumn. It means that 
students are solving a problem in a real life cases. The studying happens in small groups. For communication between the members of the group, digital $\mathrm{TV}$ is providing a real-time discussion forum.

\section{ASSESSMENT OF LEARNING}

According to Rowentree (2003), the method of assessment affects how and what students are studying. In Local Demands for Global Enterprisingcourse we are using multiple choice- questions and participating case discussions, as a criteria of assessment. With the multiple choice- questions it is possible to check how well the terminology and concepts are understood, as well as how the most important details are known covering the whole course.

The discussions show the ability of student's understanding of the subject as a whole. It also makes it possible to estimate how well students have figured out the problems in the subject and the cases used, as well as their ability to see the subject and problems analytically.

\section{CONTENT PRODUCTION}

We have had two ways to produce text material for digital TV portal. We have used both commercially available XML editors and also made our own MHP parser for producing pages. With parser the user does not have to know anything about HTML, selections from the database are picked easily with a mouse. A disadvantage is that the MHP-parser does not allow changing pages. If the user wishes to make some changes, she would have to do those with a XML editor.

Now we have a third way to produce pages with our own database for digital learning materials. This allows transferring the material for digital TV with just a few keystrokes. This database makes it easy to re-use the material made for another course. It is also possible to transfer the material for different devices, such as digital television, $\mathrm{PC}$ and mobile phones. In the database for digital learning material the LOM standard (IEEE LOMLearning Object Metadata version 6.4) is partly included. 


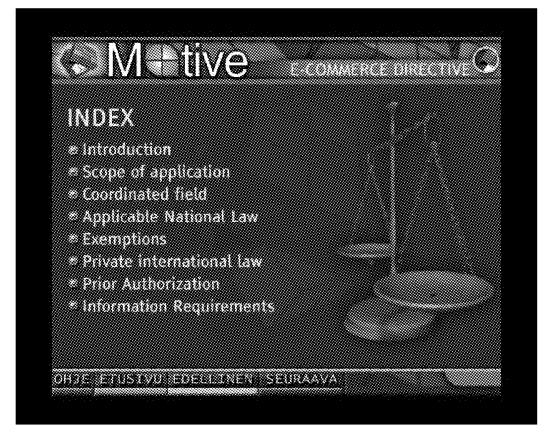

Figure 1. A sample screen from our course materials

Our new course in digital TV, Global Competencies and Interpersonal Skills in eBusiness, is produced with the help of this database. First the learning material is entered into the database and then easily, with a few keystrokes, transferred into a suitable form for digital TV.

\section{RESULTS}

Feedback from the students has been very positive and encouraging. They feel that digital television is very suitable for educational purposes and they would like to study more in digital television. They also said, that it is easy to use digital television as a learning environment. The multiple choice questions were especially liked, because the easy and fast feedback on wrong answers.

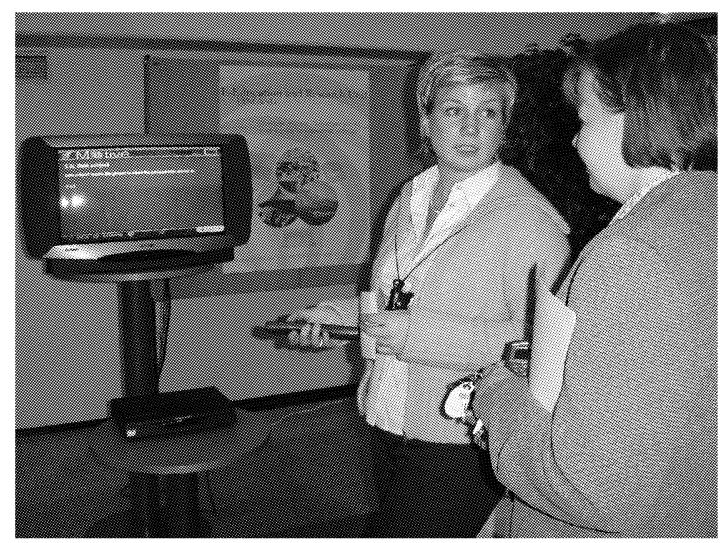

Figure 2. Users discussing the use of the learning environment. 
All of the students were very familiar with the use of Internet and text television and that might be one of the reasons why they felt that digital TV is easy to use. It took them only few minutes to learn how to navigate and study in digital TV. The structure of the course was so simple, that there was no change to get lost.

Students were hoping in their feedback, which was gathered by an inquiry form, that coloured buttons could be used to get to a previous and next page in future. In the new version of the digital television portal software, which will be used in autumn 2003 course, there are new features available that give more freedom for navigation between pages.

Students felt that seeing the normal TV broadcasting in the corners of the TV-screen was disturbing their concentration. In the new version students have the chance to choose the way the learning content is laid out on the TVscreen. It will be possible to cover the total screen, but also to have the normal broadcast shown in smaller screen in selected area of the big screen.

\section{FUTURE PROSPECTS}

During the autumn 2003 we are planning to test the use of the return channel in conversations and in delivering the assignments. Next course to be produced for digital television is "Global Competencies and Interpersonal Skills". Content production will be much easier than it was in the first course, because now tools for content production are available. It is possible to use commercially available XML editors and create suitable templates. In templates it is possible to have different kinds of layouts and it is easy to add headings, text, links and images to the templates. One important issue is also possibility to preview the content on PC before uploading to the database.

We will use both SMS and MMS-messages in Global Competencies and Interpersonal Skills-course. Digital television discussion forum application provides an environment to convey GSM based discussions in digital TV. It is possible to moderate and lead the conversation. Digital television e-mail application includes all key elements of an e-mail system and additional features, which help to send short messages including pictures from TV-toTV or TV-to MMS enabled phones.

At the moment we are building a new conversation forum for digital TV. It will be possible to use SMS, PC and digital TV for sending the messages to be seen in digital TV discussion screens. We are trying to make the learning environment in digital TV as flexible as possible for our students. If they happened to be in a place where digital TV cannot be seen, it still would be possible for them to study, with the help of i.e. a PC. 


\section{CONCLUSIONS}

Studies in digital TV combine the familiarity and ease-to-use of the existing medium and the extensive opportunities offered by the technological characteristics of the new medium. Digital TV enables a large variety of background information and additional data to be included.

The feedback from students indicates that digital TV is suitable to use as a learning environment. However, it does not mean that everything is perfect right now, but we can develop digital TV incrementally to become an interactive and personalized learning environment and will continue the research in the area.

The research includes new tools (i e identification) and methods for personalized learning, new communication tools and devices to improve interaction and use of return channel in delivering of assignments and conversations. The main issue in content production for learning is that the chosen technology is suitable for the content. Everything does not need to be the highest technology, but the technology should support the learning process and give some added value to the learning.

\section{REFERENCES}

Garito, M. A. (2001). Telematics: Digital Television and Life Long Learning. Dublin: European Education Technology Forum

Hakkarainen, K. L. \& Lipponen, L. (2001). Tutkiva oppiminen älykkään toiminnan rajat ja niiden ylittäminen. pp.175-206.

Hiltz, S. R.. (1998). Collaborative Learning in Asynchronous Learning Networks: Building Learning Communities. Keynote address to the WEB98 conference, Orlando, Florida, $\begin{array}{lll}\text { November. } & \text { Retrieved 27.2.2003 from }\end{array}$ http://eies.njit.edu/ hiltz/collaborative_learning_in_asynch.htm

IEEE. (2002). IEEE-Learning Object Metadata version 6.4 (2002, 08.05.2002). Available http://jtc1sc36.org/doc/36N0255.pdf

Rowentree, D. Designing an assessment system, Retrieved 27.2.2003 from http://iet.open.ac.uk/pp/D.G.F.Rowentree/assessment.html

\section{BIOGRAPHY}

Päivi Aarreniemi-Jokipelto is responsible for the Motive-project, which has developed the use of digital television as a learning environment. Her research interests include e-Learning, especially interaction, learning process and personalized learning as well as the use of digital television as a learning environment from both technical and pedagological sides.

Juha Tuominen is interested in the research and development of interactive digital environments including DTV, web, mobile and virtual simulation technologies. Recent 
projects of his laboratory have developed pilots in the areas of e-Learning, DTV, personal navigation (GPS \& GSM), mCommerce, logistics, and physical simulations. The diverse ICT activities of the laboratory have also yielded a large number of courses using various eLearning techniques.

Seppo Kalli is a part-time Professor at the Signal Processing Laboratory at the Tampere University of Technology, Finland. He holds a Dr. Techn. (PhD) degree in Information Technology from the Tampere University of Technology. Dr. Kalli is also a Managing Director of Ortikon Interactive Ltd., a company specialising in digital television and mobile communication technologies (www.ortikon.com). Seppo Kalli has a long history of working in the field of digital television. His research interests include digital audio-visual systems, mutimedia technologies, digital signal processing and digital communiation technologies.

Tommi Riikonen is a Vice President of Operations at Ortikon Interactive Ltd., a company specialised in digital television and mobile communication technologies (www.ortikon.com). He holds a Master of Science degree in Computer Science from the Tampere University. Tommi Riikonen has a strong knowledge of digital television systems in satellite, cable and terrestrial environments. This knowledge spreadsto the spectrum of DVB systems:production, broadcast, transmission equipment, receivers, returnpath,APIs' etc. His special researcs interests areas have been applications, user interfaces and usability in digital television environment. 